\title{
Hintikka on Descartes's Cogito
}

by Nicola Ciprotti

\section{o. Introduction.}

Cogito ergo sum is perhaps the best-known dictum of philosophy, whose meaning and import every scholar and theorist believes to have an acceptable grip with. The official story about the cogito is this: in the Second Meditation, the conclusion 'ego sum' - I exist - is derived through modus ponens by a couple of premises, namely,

(i) 'Necessarily for every $x$, if $x$ thinks then $x$ exists';

(ii) 'I think'.

The conclusion is, therefore,

(iii) 'I exist'.

Rendered this way, it seems hardly disputable the cogito amounts to a deductive inference. It does not matter - so the story carries on - that Descartes does not supply us with an explicit statement of (i)[1]; what is crucial is rather that, once (i) is made overt, the cogito really looks like an inference, by means of which every intelligent being can, in an allegedly indefeasible manner, establish its own existence. Notice, however, that the logical form of the cogito is not a syllogism (as acknowledged by Descartes himself, e.g. in Reply to the Second Set of Objections):

He who says, I think, hence I am or exist, does not deduce existence from thought by a syllogism but, by a simple act of mental vision, recognises it as if it were a thing that is known per se. This is evident from the fact that if it were syllogistically deduced, the major premise, that everything that thinks is, or exists, would have to be known previously; but yet that has rather been learned from the experience of the individual.[2]

Descartes's argument against the syllogism reading is crystal clear. If the cogito were a syllogism, it would run thus:

(i) (i*) 'Everything that thinks also exists';

(ii) (ii*) 'I think'.

Therefore

(i) $\quad\left(\mathrm{iii}^{*}\right)$ 'I exist'.

The problem with the syllogism reading is that, in order for anyone to be justified in asserting ( $\left.i^{*}\right)$, she should already know that no exception to it is possible; that means she should already have come to ruling out the possibility that she (the referent of 'I') 
is one such exception. But if one knows that she is no exception, no general premise like ( $\left.i^{*}\right)$ is needed. Thus, no one is justified in upholding $\left(i^{*}\right)$ unless she has already discovered that she exists. And since existence is to count as the conclusion of the alleged syllogism, not one of its tacit assumptions, it follows that the cogito is not a syllogism.

This is the official story about cogito ergo sum: while it not being a syllogism, it is a deductive inference none the less.

Is the official story actually true? Jaakko Hintikka has famously argued that, even if true, this story is at least incomplete.[3] According to him, Descartes's discovery of his own existence via the cogito should be regarded as a performance rather than an inference, though he submits that the performance reading is not in principle incompatible with the inference reading. His main point is, rather, that focusing on the inference reading does not render justice to the epistemological enterprise undertaken by Descartes through the cogito, that is, providing an irrefutable yet $a$ posteriori piece of knowledge.[4]

In what follows I intend to show that, both when read as an inference and a performance, the cogito proves even less than Hintikka alleges. For all that I do not take a stand over the inference vs. performance issue, I shall partially align with him in rating the cogito as a disappointing piece of reasoning, the difference being that, on my opinion, not even Hintikka's peculiar interpretation can save the cogito from epistemic defeat.

\section{The official story again: cogito as an inference.}

To start off, it is well-advised to recall the entire passage at the beginning of the Second Meditation where Descartes discovers that he himself exists.

After having supposed that he has neither senses nor a body - the upshot of the sceptical doubt at the end of the First Meditation - he writes:

I myself, am I not at least something? But I have already denied that I had either senses or a body. Yet I hesitate, for what follows from that? Am I so dependent on body and senses that I cannot exist without them? But I persuaded myself that there was nothing at all in the world - that there was no heaven, no earth, no minds, nor any bodies. Did I not, then, also persuade myself that I was nothing? Certainly not. I doubtless did exist if I persuaded myself of something or if I merely thought of something. But there is some sort of very powerful and cunning deceiver, who employs all his ingenuity to deceive me about everything. Then there is no doubt that I exist, if he deceives me; and though he deceive me as much as he likes, he can never bring it about that I am nothing as long as I think I am something. Hence, after having thought about it thoroughly and carefully examined everything, we must come to the settled conclusion that this proposition: I am, I exist, is necessarily true each time that I pronounce it or that I conceive it in my mind.[5] Does this passage disclose the aforementioned inference (i) - (iii)? If it does - so 
argues Hintikka - its logical form must be as follows. Whereas 'thinks' is treated as a first-level predicate, the statement 'I think' can be translated by the formula $|\mathrm{Pa}|$, where ' $a$ ' (a metavariable for a singular term) stands for the pronoun 'I'. According to quantification theory of classical logic, Existential Generalisation (EG) is a valid inference-schema. That is, for whatever interpretation $I$ of the singular term occurring in $[\mathrm{Pa}$, the inference from $\lceil\mathrm{Pa} \mid$ to $\lceil\exists x(x=a)\rceil$ is valid in first-order classical logic. Moreover, if we agree with the orthodox view about 'exists' (i.e. Frege's, Russell's, Quine's) that all there is to existence is codified by the classical quantifier ' $\exists$ ', the conclusion is that the individual denoted by ' $a$ ' does exist, $[\exists x(x=a)]$ just meaning ' $a$ exists'. 6$]$ Hence, from the premise that I think, it can be validly inferred that there exists an $x$ such that $x$ thinks; since such an $x$ is identified with what ' $a$ ' stands for, namely ' $I$ ', and since there is an interpretation $I^{*}$ where the denotation of ' $\mathrm{I}$ ' is me, it follows that the conclusion that I exist is formally valid. If, moreover, $[\mathrm{Pa}]$ is true, then the argument is also sound; since Descartes seems to have held that ${ }^{\mathrm{Pa}} \mid$ is in fact true for whatever thinking subject happen to entertain the statement 'I think' - it is not possible to think without existing, premise (i) above - then the argument is necessarily sound ( $I$ am, I exist, is necessarily true each time that I pronounce it or that I conceive it in my mind). (Of course, in order for Descartes to avoid a logical blunder, the necessarily sound conclusion cannot be 'I exist', or else each one's existence would be made a necessary state of affairs by way of the cogito; to qualify as necessary is, rather, the whole statement 'If I think that I exist, then I do exist'; in sum, the cogito is only concerned with a de dicto necessity, not a de re one[7]).

It is easy to realise, finally, that Hintikka's reconstruction of the cogito as an inference is driven by the pattern (i) - (iii) mentioned at the outset, the only difference being that he is more faithful to Descartes's text in suppressing premise (i).

\section{Hintikka against the inference reading.}

Strictly speaking, Hintikka does not urge that the above interpretation is flat-out astray; rather, he maintains it has little to recommend. In point of fact, he holds that, if we read the cogito as inference, namely, an instance of EG, we are confronted with an unpleasant dilemma: either the cogito is (a) question-begging or (b) not truthpreserving (quite naturally, Hintikka takes it for granted that neither a questionbegging nor a truth-dispelling chain of reasoning counts as a good inference, even if each one for independent reasons).

As to (a), Hintikka urges that, for the cogito to count as a deductive inference of some given formal language whose proof-theory purports to feature the formal counterpart of 'I exist' as theorem, any singular term occurring in the proof must refer.

Consequently, the issue is whether ' $\mathrm{I}$ ' is a singular term of the language at stake, that is, whether there be at least an interpretation $I$ such that $I$ assigns me to ' $I$ ', whereas of course I am included in the domain $D$ of objects over which the quantifier ' $\exists$ ' ranges ( $D$ thereby conceived as the set of existent objects). 
According to Hintikka, the predicament with (a) is that the existence of $I$ is guaranteed a priori, so that maintaining that 'I' is in fact a singular term is just another way of saying that I exist.[8] In a nutshell, this is so because the argument relies on classical logic, whose semantics is invariably such that, for every interpretation $I$ in a model, every singular term ' $\tau$ ' of the language is interpreted by an object $I(\tau)$ found in $D$. For, in a classical environment no singular term lacks a denotation; a fortiori, then, there will always be at least an interpretation $I^{*}$ such that 'I' denotes me according to it. Accordingly, once the premise of EG is granted, my existence will be as well, since the formal counterpart for $\lceil\exists x(x=a)$ l is satisfied by at least one interpretation. Therefore, the commitment to the validity of EG bespeaks a well-known tenet of classical logic, the non-emptiness of $D$, to the effect that, for every singular term of the language some thing must exist to which the term refers (this tenet is what Hintikka repeatedly denotes by way of the locution 'existential presuppositions').

The upshot is that cogito's conclusion, i.e., one's own existence, is tacitly understood by the premise 'I think'. Consequently, (a) urges that the proof is pleonastic, and therefore wholly dispensable with, since the statement 'I exist' carries over from premises to conclusion. To this regard, notice that Hintikka does not charge the proof with invalidity but with uselessness, for he just remarks that the proof is unnecessary, the semantics of first-order classical logic being sufficient for a priori warranting the conclusion.

What if, then, should we decide to free the proof from the existential presuppositions built in the semantics of classical logic, and thereby to resort to free logics in order to assess the validity of the inference? This is horn (b) of the dilemma; it consists in recognition that, as soon as no existential commitment is being involved in ' $I$ ', truth is not preserved from premises to conclusion, and hence the proof is formally invalid. Hintikka argues in fact there is no principled reason why the proof should go classical. For nothing interferes with treating 'I' as a non-denoting, or even a nonreferring, singular term. In the former case, 'I' counts as a term which lacks a denotation in the domain $D$ of existent objects, while it has a denotation in the different domain $D^{*}$ of non-existent objects; in the latter case, 'I' is altogether nonreferential and will qualify as mere flatus vocis. Be 'I' read as non-denoting or nonreferring, the upshot is one and the same: EG is no more valid because 'I' does not fall inside the scope of ' $\exists$ '. As soon as ' $I$ ' is freed from existential presuppositions, therefore, the cogito gets interesting and pointed but in fact invalid.[9] As he puts it The truth of [EG] turns entirely on existential presuppositions. If they are given up, the provability of [EG] goes by the board. My point may perhaps be illustrated by means of an example constructed for us by Shakespeare. Hamlet did think a great many things; does it follow that he existed?[10]

Hintikka's point is clear. Even if Shakespeare had so arranged the eponymous tragedy in such a way as to make Hamlet go into the cogito reasoning, we could not conclude that Hamlet exists. As a matter of fact, Hamlet's possible use of (any occurrence of) 'I' in a cogito-style reasoning would be non-denoting, albeit referring (to himself). 
Accordingly, even granting it is true that Hamlet thinks, still we are not allowed inferring that 'I exist' is true when 'I' refers to Hamlet; for 'I' functions here as a nondenoting term - in fact, Hamlet does not exist. Hence, in Hamlet's case - that is, according to a free logic - the cogito does not presuppose the truth of its conclusion, yet it is formally invalid because it has a true premise and a false conclusion (the same holds a fortiori when 'I' is treated non-referentially).

To see more vividly why, in general, the proof is invalid in a free logic, i.e. one free of existential presuppositions, consider the following case.

Suppose that in the far future an alien, intelligent form of life comes across Descartes's Second Meditation; suppose further that such beings are able to understand Medieval Latin, or Old French, so that they can read and understand the cogito passage. What would they learn? Would they conclude that the author of the text exists, or existed once? Hardly so. In fact, the cogito cannot by itself put them in a position to know whether the author of the cited passage had ever actually thought (felt, perceived, doubted, etc.) or not. In general, no one could tell, just by the chain of reasoning displayed in the cogito passage, whether the author of the words 'I am, I exist' does so in propria persona or on behalf of someone else. To this regard, suppose in fact that the aliens have no acquaintance at all with the history of our species. Upon reading the cogito, it is entirely consistent with their newly acquired beliefs that they still refused to conclude to the non-fictional existence of Descartes. On the other hand, were they to know per impossibile that those thoughts and words are commonly attributed to a fellow known as Hamlet the Dane, they would not be able to infer that it has not been Hamlet to once think and write them, and therefore to exist, but rather his literary father.

The morals Hintikka wants us to draw from (b) is therefore that, as soon as the cogito breaks free of existential presuppositions, we are in the same boat as the aliens: the cogito is unable to tell us whether or not Descartes and Hamlet differ as to their respective ontological status. For all we can learn from the cogito, they might have been both actual, or both fictional (or even had their roles switched: Hamlet the philosopher, Descartes the fictitious Prince of Denmark). Aside from being logically flawed - because it is unwarrantedly biased in favour of classical logic - the cogito is, therefore, also informally unconvincing because it is silent over whether its utterer is an actual being or just a fictional character.

Thus - this is Hintikka's conclusion - when regarded as an inference the cogito is either a petitio principii or a non sequitur. Either case, a bad inference.[11]

\section{Cogito as an existentially self-verifying statement.}

Let us take a brief stock. On the face of it, Descartes's discover of his own existence via the cogito is an inference stemming from two premises: (i) ex nihilo nihil fit, namely, thinking entails existing; (ii) I think. We have seen that Hintikka challenges that reading: if this is really the name of the game, then either the inference is 
classically behaved, or not. If the former, then (a) the cogito is too weak because it presupposes the truth of its conclusion; if the latter, then (b) the cogito entails the conclusion that fictional characters exist in the same manner as actual people do. Since that conclusion is plainly false, it follows that, if the cogito is not classically behaved, then it is invalid.

I think that, even if Hintikka is right on (b) (but see the previous footnote), still option (a) is debatable. In particular, I purport to show that, as an inference, the cogito is even weaker than Hintikka takes it to be. Secondly, I intend to show that, for parallel reasons, not even his revisionary interpretation of the cogito makes it more cogent. In sum, I wish to argue that, be it an inference or a performance, the cogito is too deeply defective to qualify as the rock-bottom take-off to Descartes's metaphysical enterprise.

Coming now back to Hintikka: what is the cogito, if not an inference? Although a debate was triggered by his provocative suggestion,[12] I shall limit myself to summarising Hintikka's account as perspicuously as possible.

In order to explain the nature of cogito, Hintikka introduces the notion of 'existential inconsistency'. Even though such a notion has been criticised on the grounds that, after closer scrutiny, it turns out to be quite problematic, its intuitive meaning seems clear-cut enough. Basically, existential inconsistency is a relation between a declarative sentence, an utterer, and a time; a sentence $S$ is existentially inconsistent iff (i) $\mathrm{S}$ is a declarative sentence, (ii) for any time $t$ and utterer $u$, there is a singular term ' $\tau$ ' in S such that $u$ uses ' $\tau$ ' in $\mathrm{S}$ to refer to herself at $t$, (iii) $\mathrm{S}$ is inconsistent for the referent of ' $\tau$ ' to utter. Thus, a consistent sentence $S$ containing singular terms referring to the utterer of $\mathrm{S}$ becomes existentially inconsistent as soon as $\mathrm{S}$ is uttered by the denotation of the singular term involved. A couple of examples will make all this clearer. The declarative sentence 'Charlie is not speaking at $t^{\prime}$ is in itself consistent. It is changed into an existentially inconsistent one iff 'Charlie' refers to the utterer at $t$ of the sentence 'Charlie is not speaking at $t$ '; in point of fact, Charlie is speaking at $t$; the declarative sentence 'Bill Clinton does not exist at $t$ ' is in itself consistent. It is changed into an existentially inconsistent one iff 'Bill Clinton' refers to Bill Clinton, and Bill Clinton utters at $t$ the sentence 'Bill Clinton does not exist at $t^{\prime}$.

Existentially inconsistent sentences are, for Hintikka, self-defeating.[13] Accordingly, an external negation of a self-defeating sentence $S$ gives rise to a self-verifying sentence, that is, a sentence $S^{*}$ such that, for any utterer $u$ and listener $l$, if $u$ utters $S^{*}$ in an attempt to having $l$ believe in $\mathrm{S}^{*}$, then the very uttering of $\mathrm{S}^{*}$ on the part of $u$ has $l$ believe in $S^{*}$.

Cogito ergo sum is the paradigm case of a self-verifying sentence:

[...] as existentially inconsistent sentences defeat themselves when they are uttered or thought of, their negations verify themselves when they are expressly uttered or 
otherwise professed. Such sentences may therefore be called existentially selfverifying.[14]

For, the very uttering of 'Cogito ergo sum' makes it broadly logically impossible that the following states of affairs both obtain: My not existing at $t, M y$ considering at $t$ the possibility that I do not exist at $t$. Hence, cogito verifies itself as soon as any subject entertains it. The cogito comes therefore very close to a brute fact: that one is existing is a state of affairs that, according to him, cannot be secured through any kind of prior reasoning. This is why he calls cogito a performance, an intellectual experience of a special sort, [15] or some kind of an intuition: the statement 'I exist' is not detachable from the very evidence that warrants it; 'I exist' is true anytime I do something (again, grant 'doing' and 'something' wide scope). Existential selfverifiability is, thus, primitive and immediate, not the result of a chain of reasoning. It is not that I intellectually perceive myself as an existing thing through thinking; thinking is not the means for existing. To the contrary, to fall short of thinking is ipso facto to put an end to the way in which existence reveals itself. According to Hintikka, the difference between thinking as a means for, and thinking as a manner of, existing is crucial.[16] If that difference is neglected, we could not make sense of Descartes's refusal of taking thought and existence as merely overlapping, since he famously urged that what cogito purports to show is that one's whole essence consists entirely in thinking (his alleged proof that sum igitur praecise tantum res cogitans).[17] Thus, if one is in any thought-activity whatsoever (whereas 'thought-activity' should be conferred wide scope again: not only e.g. 'doubting' or 'being deceived', but also 'perceiving', 'feeling', and the like - sentire, as Descartes sometimes says), there is no interesting inference to be drawn: thinking (wide scope) equals to existing, to wit, to being something rather than nothing. Accordingly, the conclusion 'I exist' is not inferred from 'I think' since the predicate 'exists' is necessarily coextensive with 'thinks' - necessarily, the two statements have the same truth-conditions.

\section{Thinking without existing.}

I do not wish to take issue with Hintikka's revisionary account of the cogito. Perhaps, just an empiricist prejudice lurks behind his refusal of granting the cogito the inference status; it is in fact a dogma of empiricism that no existential sentence can be analytic, so that if one such appears as a theorem in a derivation, it is alleged that something has gone wrong somewhere else. This bias, therefore, could have motivated him both in advancing a free-logic treatment of the inference at stake, thereby invalidating it, and his revisionary interpretation of the cogito, according to which contingent existence cannot ever be matter of logic alone. And, after all, he might well be really right, if only because he is so cautious as to admit that both readings suit (different places of) Descartes's text.[18]

Be this as it may, I believe that a counterexample can be levelled against both readings of the cogito. Therefore, I intend now to show (A) that the cogito is invalid even when made to rely on EG (contrary to Hintikka, who instead argues that the cogito is classically valid); (B) that the selfsame counterexample applies mutatis to 
Hintikka's proposal, so that the alleged performatory nature of the cogito is immaterial to the issue whether it be necessarily true: in fact, I think the cogito is not even self-verifying.

Let's focus on (A). To this regard, while Hintikka believes that, as an inference of classical logic, the cogito merely begs the question, I suspect its drawback to be graver. If the following is on the right track, we must conclude that, in the way stated by Descartes, the cogito does not prove the utterer's own existence, not even by the lights of classical first-order logic; a fortiori, therefore, it does not provide indefeasible evidence for that conclusion, either. Hence, the cogito lacks the selfevidence Descartes thought it has.

If the counterexample forthcoming is sound, moreover, the cogito will turn out invalid for stronger reasons than the ones advocated by Hintikka in horn (b) of his dilemma, namely, that Hamlet thinks but does not exist. At this stage, though, a little digression is in order. As a matter of fact, his argument against the validity of the cogito involves the debatable assumption that fictional entities and concrete actual beings can satisfy ordinary first-level predicates, e.g. 'thinks', much in the same way. A good deal of theorists, however, would balk at that assumption. According to the pretence-theoretic account of fiction, for example, predicates ascribed to characters of fiction are not literally satisfied by them; for, pretence theorists allege that, in fictional discourse, we just engage in the pretence that what stories are about is really the case. Thus, they claim that novelists just make believe that what the story claims to be true is in fact true; for instance, we should not believe that Hamlet did ever wonder (whereas wondering is a kind of complex brain activity which does qualify as a special case of thinking) Whether 'tis nobler in the mind to suffer / The slings and arrows of outrageous fortune, / Or to take arms against a sea of troubles. According to them, Hamlet is not here really making up his mind about whether to revenge his father by killing King Claudius, or not; we just pretend he does, being nevertheless ready to add that he does not, strictly speaking, think and wonder. In fact, he is involved in no genuine cognitive activity.[19]

I do not claim that the pretence-theoretic account of fiction is right; I only want to stress that, if the sole reason why Hintikka regards the cogito as an invalid inference is that, according to free logics, fictional objects may think without existing in flesh and blood, then his argument can be resisted in the first place, since it is far from obvious that Hamlet, King Claudius, or their likings, do think. To the extent, therefore, that his case against the cogito is insensitive to the distinction between truth-in-fiction and truth simpliciter, it is not fully convincing. Thus, we must look elsewhere for a better case.

We are in fact seeking for a counterexample displaying a more robust sense of thinking, as it were. If it can be shown that a case is possible where thinking (or something very close to it) takes place without involving the concrete existence of a thought-owner, then the upshot will follow that the cogito is invalid, even without resorting to the contentious assumption that genuine thought can be ascribed to 
fictional entities. The case I have in mind can be sketched thus.

Suppose you are sleeping and dreaming safe in your bed, just as Descartes pretends that he might be doing throughout a good deal of the First Meditation. Suppose further that your dream concerns a person, who is not you - you know that (compare: when dreaming, most of us sometimes know within the dream itself that what is occurring to them is just a dream, thereby feeling relieved or discomforted by such a belief - depending on what the dream is about). I now ask you to imagine a circumstance in which, while dreaming, you know quite in the same way that the sole protagonist of your dream - the only person to appear in it - is not you. As far as we know, this circumstance is surely possible, both empirically and logically: the brain of actual human beings could have those experiences; nothing in the description of this dream involves a formal contradiction.[20] Call such a person 'Person' - 'Person' is just a placeholder: we need not know her name; just bear in mind you are not Person. Accordingly, in the dream you totally lack her first-person perspective: you cannot feel what Person feels, see what Person sees, hear what Person hears, and so on: you are third-person with respect to her. In a way, it is as if you were just the spectator of a play, watching at actors performing on stage, the only difference being the only actor here is Person.

What you experience Person doing during the dream is just this: rehearsing the cogito passage word by word. Consequently, there comes the moment at which Person says

I doubtless did exist if I persuaded myself of something or if I merely thought of something. But there is some sort of very powerful and cunning deceiver, who employs all his ingenuity to deceive me about everything. Then there is no doubt that I exist, if he deceives me.

Et cetera. At the end of the cogito passage, your dream comes to an end as well, and you wake up. Once back to wake, you recall the dream to your mind; what should you conclude about it?

As we know, the conclusion to be drawn should be that, upon unfolding to herself the whole passage, Person has discovered her own existence; in fact, Person has realised that the evil genius might well deceive her about everything, save than this: that she herself exists, if it were really true that she suspected she could not, etc.

The strongest intuitions of most of us, however, will not pull towards this conclusion, since we agree (don't we?) that Person does not exist; on the relevant sense of 'existing' (I mean, the one endorsed by Descartes and Hintikka alike), it is in fact you to exist, and you only. However, the case from the dream shows that it wasn't you to entertain the cogito, but someone else. (This is so, I take it, by definition: we assumed you lack Person's first-person perspective). Notice that this marks a salient difference between Person and Hamlet: while we saw there are reasons for denying Hamlet genuine cognitive activity, it is much less so as regards Person. To be sure, Person's 
entertaining the cogito is (i) a mental event, and (ii) a mental event more intimately related to Person than Hamlet's possible cogito to Hamlet, for the latter would plainly be Shakespeare's only. Still, dreaming is cognitive activity (once again: wide scope to 'cognitive'); as Descartes would put it, dreaming is a kind of sentire, however degenerate. There is no corresponding mental activity occurring in Hamlet's putative case of rehearsing the cogito; quite to the contrary, it is hardly deniable that mental activity does occur during your dream. Indeed, there occurs a dream just because someone is experiencing mental events. What's interesting here is that we face a bifurcation: it is you to have those mental events constituting the dream, it is not you to experience those mental events which, for Descartes, are self-evident warrant for the existence of their owner. Allegedly, though, the owner has to be identified with Person, not you. What does all this show? Well, scarcely is it contestable that, were Hamlet to entertain the cogito, he would not be speaking in propria persona. Differently, it is much more difficult to deny that, in a sense, Person does speak in propria persona: unlike Hamlet, mental events do occur in the meantime Person is rehearsing the cogito.

On the other hand, the suggestion that, through the cogito, Person did discover your existence instead of her own must be rejected. This is why - as hinted at earlier - the dream case even defeats the alleged classical validity of the cogito. For, if the cogito is to count as a valid instance of EG, the denotation of the singular term occurring in it must be kept fixed throughout, on pain of fallacy; to the contrary, the scenario in which Person discovers your, not her, existence involves an ignoratio elenchi, since the denotation of 'I' would in-between switch from dreamt to dreamer. This equivocation makes the inference trivially invalid; I take it that no interpretation of the cogito, however revisionary, could be more uncharitable to it than that fallacy.

We can therefore conclude that either Person discovers her own existence, or the cogito is invalid. If (I dare add: and only if) we cannot make sense of the claim that Person really exists (as Descartes and Hintikka surely don't), then the further step to be taken seems to be that Descartes's epistemological enterprise, to the extent that it is grounded upon the cogito, is unsuccessful: while he took the content of the Second Meditation as supplying unshakeable evidence against the threat of global scepticism, we now find out that the cogito displays a poor outcome, in that it merely licences the conclusion that a thought is occurring to someone, somewhere, somehow, without any ultimate warrant about the ontological status of the owner of that thought. This does not equal to asserting that the cogito is so misconceived that it falls short of even concluding to the existence of someone. After all, we take it as analytic that thoughts exist only because thinkers do (as holes exist only because surfaces do, and so on). The point at stake is rather that, however well or poorly the cogito fares about the $\mathrm{Am}$ I dreaming or not? topic, it fails to settle the quite different issue Am I a dreamt person or not?. To the extent that, as I have been trying to show, it is silent over the latter one, we should conclude that cogito's import is even narrower than Hintikka's charge, since all it shows is that some one exists, not necessarily to be identified with cogito's utterer. 
Let's now consider (B): How does cogito-as-performance fare against the above counterexample? Not much better. To see this, only slight adjustments are needed. Recall from the previous section that cogito is for Hintikka a self-verifying statement. This means there corresponds to it a self-defeating statement, namely, 'I think but I do not exist'. The latter is such that, were any epistemic agent to utter it (even to just herself, as according to Descartes's sense for 'meditatio', a conversation of the soul with itself) in an attempt to making anyone (a fortiori, oneself) assent to what it is thereby asserted, the attempt would necessarily fail. The very entertaining (with oneself) or uttering (to someone else) of the statement 'I do not exist' on the part of the referent of 'I' defeats that very attempt.

Is this so even in the case of Person? We granted that, unlike fictional characters, Person is actually engaged in thought-activity, since it is apparent that thinking is taking place right at the time of her uttering 'I do not exist now', thus fulfilling the simultaneity requirement for self-defeating statements. If cogito amounts to a performance, then we need to revise the dream scenario this way: Person is no more watched at by the dreamer while rehearsing the cogito; rather, Person is addressing the very dreamer and trying to convince her that she (i.e. Person) does not exist. Again, the difference with Hamlet is undeniable: Person is having experiences, not so Hamlet. Recall the bifurcation mentioned above: the dream is so conceived as to license the claim that the dreamer is interacting with someone endowed with (partially, I submit) independent cognitive activity; for, even though the dreamer is counterfactually responsible for the existence of Person, she is much less so as regards Person's outputs in the dream. In a sense (and barring alleged empirical theory about dreaming) the dreamer can interact with Person in a way Shakespeare could not in respect to Hamlet: while Hamlet is accredited only with those words Shakespeare did or would write, Person seems capable of more autonomous activity. As already said, nothing prevents us from supposing Person uttering 'I do not exist' and the dreamer listening to those words, interacting with Person, and so on.

What does that show? If cogito is self-verifying, then we should conclude that 'I do not exist' defeats itself even when uttered by Person, since, after all, both the dreamer and Person seems suitable values for the quantified statements 'any utterer' and 'any listener' in the above definitions. The upshot would then be, once again, that Person exists. We agreed, instead, that Person does not exist in any interesting sense meant by Descartes's employment of the cogito. For, if the cogito was ever meant by him to count as the only item to survive the general overthrown of beliefs,[21] scarcely could it serve that purpose if unable to tell whether she who thinks is or not a dreamt person.

\section{Conchusion.}

To sum up. For Hintikka, cogito ergo sum is invalid only if deprived of existential presuppositions, non-existent objects like fictional characters being the counterexample. We have taken pains to showing that the cogito is invalid even in presence of such presuppositions, dreamt people being the counterexample. 
Moreover, we also set out to show that the cogito is unable to provide an intelligent being with indefeasible certainty of her own existence even when regarded as a primitive intuition rather than an inference. It seems, therefore, we have to conclude that not even Hintikka's ingenuous interpretation of the cogito is successful in turning it into an appealing starting point for foundationalist programmes in epistemology.

\section{References}

Currie 1990. Gregory Currie, The Nature of Fiction, Cambridge University Press, Cambridge. Everett - Hofweber 2000. Anthony Everett, Thomas Hofweber eds., Empty Names, Fiction, and the Puzzles of Non-Existence, CSLI, Stanford.

Feldman 1973. Fred Feldman, On the Performatory Interpretation of the Cogito, Philosophical Review 82: 345-363.

Frankfurt 1966. Harry Frankfurt, Descartes's Discussion of His Existence in the Second Meditation, Philosophical Review 75: 329-356.

Frankfurt 1970. Harry Frankfurt, Demons, Dreamers, and Madmen, Princeton University Press, Princeton - Oxford.

Hintikka 1959. Jaakko Hintikka, Existential Presuppositions and Existential Commitment, Journal of Philosophy 56: 125-137.

Hintikka 1962. Jaakko Hintikka, Cogito, Ergo Sum: Inference or Performance?, Philosophical Review 71: 3-32.

Hintikka 1963. Jaakko Hintikka, Cogito, Ergo Sum as an Inference and a Performance, Philosophical Review 72: 487-496.

HR I, II. The Philosophical Works of Descartes - volume I, trans. by Elisabeth Haldane and G.R.T.

Ross, New York, Dover 1955.

van Inwagen 2002. Peter van Inwagen, Existence, Ontological Commitment, and Fictional Entities, in Michael Loux, Dean Zimmerman eds., The Oxford Handbook of Metaphysics, Oxford - New York: 131157.

Lambert 2001. Karel Lambert, Free Logics, in Lou Goble ed., Philosophical Logic, Blackwell, Malden Oxford 2001: 258-279.

McGinn 200o. Colin McGinn, Logical Properties, Oxford University Press, Oxford - New York. Morscher 2001. Edgar Morscher, How Can 'a exists' Be False?, in Building on Frege: New Essays about Sense, Content, and Concepts, Albert Newen, Ulrich Nortmann, Rainer Stuhlmann-Laeisz eds., CSLI, Stanford: 231-250.

Nakhnikian 1969. George Nakhnikian, On the Logic of Cogito Propositions, Nous 3: 197-210. Quine 1953. Willard van Orman Quine, On What There Is, in Willard van Orman Quine, From a Logical Point of View, Harvard University Press, Cambridge MA: 1-19.

Thomasson 1999. Amie Thomasson, Fiction and Metaphysics, Cambridge University Press, Cambridge.

Walton 1990. Kendall Walton, Mimesis as Make-Believe, Harvard University Press, Cambridge MA. Zalta 1988. Edward Zalta, Intensional Logic and the Metaphysics of Intentionality, MIT Press, Cambridge MA.

[1] At least, not in the Meditationes; the explicit statement is to be found in the well-known passage of Principia philosophiae, I, 10: pour penser il faut être. By the way, not even the saying cogito ergo sum can be found anywhere in the Meditationes, the passage to be quoted shortly being the closest formulation of it.

[2] HR, II: 38.

[3] Hintikka 1962, Hintikka 1963.

[4] Hintikka 1962: 8-9.

[5] HR I: 150. 
[6] As a matter of fact, it has been recently stressed that, while tracing back to the mentioned genealogy, the orthodox view about 'exists' does not find its first explicit spelling prior to Hintikka 1959: see Morscher 2001: 248.

[7] On the disambiguation of the two kinds of necessity involved see Frankfurt 1966: 341.

[8] Hintikka 1962: 8.

[9] Hintikka 1962: 7. For a first approach to the class of logics for non-denoting singular terms see Lambert 2001.

[10] Hintikka 1962: 8. A brief remark: Hintikka takes wholly for granted that Hamlet does not exist.

This is no surprising but, perhaps, too hasty. According to a standard criterion of ontological commitment (Quine 1953), one is ontologically committed to the objects over which the quantifiers in our best theories of everything range. Now, granted that Hamlet is a fictional entity, to see whether or not we should accept fictional entities as existing - that is, as governed by ' $\exists$ ' - we should look at whether or not we do accept quantified statements that range over such entities. And Hintikka seems to accept one such! In fact, he concedes it is true that Hamlet thinks. Therefore, there emerges a tension between that criterion, his statement, and the non-existence of Hamlet. I shall not pursue this issue any longer and grant for argument's sake that Hamlet does not exist, since Hintikka's claim is sensible none the less: since the cogito is not concerned with abstract entities of any genre, and since in the actual world Hamlet is an abstract particular, it is safe to maintain that, by these lights, he does not exist.

[11] More recently, Colin McGinn has charged the cogito with the same bleak upshot, viz. questionbeggingness or invalidity: McGinn 2000: 45-47; notice, however, that the account of existence McGinn provides there is at loggerheads with Hintikka's.

[12] Hintikka 1963, Frankfurt 1966, Nakhnikian 1969, Feldman 1973.

[13] I am here following Feldman in his attempt to making the meaning of 'existential inconsistency' clearer: Feldman 1973: 350 ff. For further comments see Frankfurt 1966: 330-331.

[14] Hintikka 1962: 15.

[15] Feldman 1973: 358.

[16] Hintikka 1962: 22.

[17] Hintikka 1962: 16-19. In order to be faithful to Descartes's ultimate aim, be careful not to read 'existence' as synonym of 'bodily existence', for if there is anything the cogito purports to show is the possibility of disembodied yet concrete existence, the animae a corpore distinctio advertised for from the very title of the Meditationes.

[18] Hintikka 1962: 8.

[19] Pretence theory is championed by Walton 1990, Currie 1990. It might be reasonably contended, moreover, that neither object theorists (for example Zalta 1988, Thomasson 1999, van Inwagen 2002) are committed to the belief that Hamlet thinks in the sense that is necessary for the validity of the cogito. Object theorists would rather maintain that such abstract entities as creatures of fiction have or encode properties without instantiating them, that is, being concrete tokens of the qualities, statuses, processes, natures at stake, to the effect that encoding the property of thinking does not entail anything entailed by (or simply involved with) any instance of the cogito. For a survey of the ongoing debate about creatures of fiction and related issues, see Everett - Hofweber 2000.

[20] Non-contradictoriness is perhaps even unnecessary, since the content of some actual dreams is not immune from violations of it, as everyone knows.

[21] 'Ever', since it is well-known that Harry Frankfurt has fascinatingly and forcefully contrasted such a widely-held view about Descartes's overall aims in the Meditationes: Frankfurt 1970.

Nicola Ciprotti got his Ph.D. in analytic philosophy from the University of Florence, Italy. He is currently post-doctoral Lise Meitner fellow in the department of philosophy at the University of Salzburg, Austria. He has published papers in metaphysics and philosophical logic. 